\title{
An analysis of multiplex-PCR in the detection of BCR-ABL transcripts in hematological disorders
}

\author{
Darío A. Sastre ${ }^{1}$, Carlos E. Argaraña ${ }^{2}$, Viviana B. Heller ${ }^{1}$, Mónica Gallo ${ }^{3}$, Enrique N. Fernández ${ }^{1}$ \\ and Cecilia M. Rodríguez ${ }^{1}$ \\ ${ }^{1}$ Laboratorio de Oncohematología, Hospital Nacional de Clínicas, Facultad de Ciencias Médicas, \\ Universidad Nacional de Córdoba, Córdoba, Argentina. \\ ${ }^{2}$ Departamento de Química Biológica - CIQUIBIC, CONICET, Facultad de Ciencias Químicas, \\ Universidad Nacional de Córdoba, Córdoba, Argentina. \\ ${ }^{3}$ Servicio de Oncohematologia, Instituto San Agustín, Universidad Católica de Córdoba, Córdoba, \\ Argentina.
}

\begin{abstract}
In this work, we describe the advantages of multiplex-PCR in the specific detection of BCR-ABL transcripts in different hematological disorders and its sensitivity compared to nested PCR. Fifty-three patients were studied for the presence of BCR-ABL transcripts: 24 patients with chronic myeloid leukemia (CML), 20 with acute leukemia (AL), and 9 patients with other hematological disorders. A variant rearrangement (b3a3) was found in a single case of CML (4.2\%). Four out of the 20 patients with AL (20.0\%) (14 adults, 6 children) were bcr-abl(+), and in this group three cases were classified as B-acute lymphoblastic leukemia (B-ALL), and one as acute myeloblastic leukemia (AML). Two of the three patients with B-ALL were positive for b2a2 and the other one for e1a2, while in the BCR-ABL(+)AML patients a b3a2 rearrangement was observed. In conclusion, multiplex-PCR allows rapid, specific and simultaneous detection of different types of BCR-ABL transcripts in CML and ABL-BCR(+)AL. A full correlation was observed when multiplex-PCR was compared with nested PCR.
\end{abstract}

Key words: multiplex-PCR, Ph chromosome, BCR-ABL, chronic myeloid leukemia, PCR.

Received: August 22, 2006; Accepted: January 31, 2007.

\section{Introduction}

The Philadelphia $(\mathrm{Ph})$ chromosome that results from a reciprocal translocation involving the long arms of chromosomes 9 and 22, $\mathrm{t}(9,22)(\mathrm{q} 34, \mathrm{q} 11)$, is one of the most frequent cytogenetic abnormalities in hematological disorders (Rowley, 1973). It is found in $98 \%$ of chronic myeloid leukemias (CML), $20-40 \%$ of adult acute lymphoblastic leukemias (ALL), $5 \%$ of childhood ALL, and $2 \%$ of myeloblastic leukemias (AML) (Léglise et al., 1996). At the molecular level, $t(9,22)$ is characterized by the fusion of the proto-oncogene ABL (9q34.1) and the breakpoint cluster region (BCR) at band 11.2q of chromosome 22, giving rise to a chimeric gene, BCR-ABL, which is translated into a fusion protein with transforming ability (Crist et al., 1990). The abnormal fusion gene leads to the expression of three different types of BCR-ABL transcripts. In all cases, the $\mathrm{ABL}$ exon 2 is involved and fused with the $\mathrm{BCR}$ gene.

Send correspondence to Cecilia Rodríguez. Laboratorio de Oncohematologia, Hospital Nacional de Clínicas, Santa Rosa 1564, 5000 Córdoba, Argentina. E-mail: labhemato@fcm.unc.edu.ar/ cecirodr@hotmail.com.
In CML, the breakpoint in BCR is located in the major breakpoint cluster region (M-BCR), in which either $\mathrm{BCR}$ exon $\mathrm{b} 2$ or $\mathrm{b} 3$ is fused to the $\mathrm{ABL}$ exon $\mathrm{a} 2$, giving rise to two main types of transcripts: $\mathrm{b} 2 \mathrm{a} 2$ or $\mathrm{b} 3 \mathrm{a} 2$, which are translated into a fusion protein of $210 \mathrm{kDa}(\mathrm{p} 210)$. In $8.5 \%$ of the cases, both transcripts can be detected simultaneously, as a result of an alternative splicing process (Léglise et al., 1996).

Approximately $70 \%$ of Ph-positive ALL cases have breakpoints that result in the fusion of BCR exon e1 to ABL exon a2 (e1a2 transcript), which encodes a smaller (190 kDa) BCR-ABL protein (p190) (Saglio et al., 1996). The remaining $30 \%$ have rearrangements that are identical to those in CML.

Polymerase Chain Reaction (PCR) is a rapid and sensitive method used for in vitro amplification of size-limited DNA segments (Kawasaki et al., 1988). Cross et al. (1994) described a multiplex-PCR assay for the identification of BCR-ABL transcripts that allows the simultaneous detection of two or more genes in the same reaction. 
In this study, we analyzed the advantages of multiplex-PCR in the detection of BCR-ABL rearrangements in hematological disorders at diagnosis. In addition, we evaluated the reaction sensitivity compared to nested PCR.

Following approval by the local research ethics committee, peripheral blood or bone marrow samples from 53 patients diagnosed at the Oncohematology Service of Hospital Nacional de Clínicas of Córdoba (Argentina) were studied at diagnosis: $24 \mathrm{CML} ; 2$ essential thrombocythemia (ET); 3 myelofibrosis (MF); 20 acute leukemia (AL) (14 lymphoid and 6 myeloid); 2 myelodysplastic syndromes (MDS), and 2 myeloid leukemoid reaction (MLR). The mean age of the patients was 41 years, ranging from 5 to 87 . Samples were processed immediately after collection. All CML patients were in chronic phase at diagnosis. Different samples were allowed from one patient during disease follow-up.

Total cellular RNA was extracted from $5-10 \times 10^{6}$ blood or bone marrow leukocytes by the Chomczynsky and Sacchi method (1987). The amount and quality of RNA were controlled by $260 / 280 \mathrm{~nm}$ OD measurement. For the reverse transcription reaction, $20 \mu \mathrm{L}$ of RNA $(5-15 \mu \mathrm{g})$ were incubated in the presence of $5 \mathrm{mM}$ Tris buffer $(\mathrm{pH}=8.3) ; 75 \mathrm{mM} \mathrm{KCl} ; 3 \mathrm{mM} \mathrm{MgCl} 2 ; 1 \mathrm{mM}$ DTT; $120 \mu \mathrm{g} / \mathrm{mL}$ random primers (Amersham-Pharmacia); $0.2 \mathrm{mM}$ dNTP (Promega); 1.4.10 $\mathrm{U} / \mathrm{mL}$ M-MLV reverse transcriptase (Promega), and $1400 \mathrm{U} / \mathrm{mL}$ RNAsin (Promega), in a final volume of $40 \mu \mathrm{L}$, at $37^{\circ} \mathrm{C}$ for $2 \mathrm{~h}$. The reaction was stopped by heating to $65^{\circ} \mathrm{C}$ for $10 \mathrm{~min}$, and the resulting cDNA was stored at $-20^{\circ} \mathrm{C}$. A negative control (water instead of RNA) was included in all reactions (Cross et al., 1994; Cross, 1996). Multiplex-PCR was performed as previously described (Cross et al., 1994; Cross, 1996). Briefly, $5 \mu \mathrm{L}$ of cDNA were mixed with $20 \mu \mathrm{L}$ of PCR-Mix containing $10 \mathrm{mM}$ Tris- $\mathrm{HCl}$ (pH 8.3); $50 \mathrm{mM} \mathrm{ClK}$; 1.5-2.5 $\mathrm{mM} \mathrm{MgCl} 25 \mu \mathrm{M}$ of each primer (CA3-, B2B, C5e-, and BCR-C) (Bio-Synthesis); $0.2 \mathrm{mM}$ of each dNTP (Prome$\mathrm{ga}$ ), and $30 \mathrm{U} / \mathrm{mL}$ of Taq polymerase (Promega) and then submitted to 35 cycles in a thermocycler (MJ Research). Cycle times and temperatures for denaturation, annealing and synthesis were $30 \mathrm{~s}$ at $96{ }^{\circ} \mathrm{C}, 50 \mathrm{~s}$ at $60{ }^{\circ} \mathrm{C}$ and $1 \mathrm{~min}$ at $72{ }^{\circ} \mathrm{C}$, respectively, followed by a $10 \mathrm{~min}$ extension at $72^{\circ} \mathrm{C}$. Two positive controls and two blank controls were included in all reactions. In order to detect false-negative results and compare the transcript type obtained by multiplex-PCR, all samples were assayed with other two separate specific amplification reactions (nested PCR): One for the detection of the $\mathrm{b} 2 \mathrm{a} 2$ and $\mathrm{b} 3 \mathrm{a} 2$ transcripts (p210), and another for the e1a2 transcript (p190) (Cross, 1996). The PCR products were electrophoresed on $1.8 \%$ agarose gel stained with ethidium bromide and visualized under UV illumination. Bands of 481 bp, 385 bp, 310 bp and 808 bp were observed for e1a2, b3a2, b2a2 and normal BCR, respectively.
To evaluate the sensitivity of both methods (multiplex-PCR and nested PCR), we diluted BCR-ABL-positive cells in BCR-ABL-negative cells ranging from $1 / 10$ to $1 / 10^{6}$.

The BCR-ABL transcripts were detected by multiplex-PCR in all patients with CML at diagnosis. In other chronic myeloproliferative syndromes, such as MF and ET and 2 cases of MDS and MLR, only a band corresponding to the normal BCR gene was observed.

Table 1 summarizes the distribution of the BCR-ABL transcripts. Among the CML patients $(\mathrm{n}=24), 41.7 \%$ $(\mathrm{n}=10)$ showed a b2a2 rearrangement, while $37.5 \%(\mathrm{n}=9)$ showed a b3a 2 rearrangement. In 2 patients with CML (8.3\%), two bands corresponding to both rearrangements (b2a2 and b3a2) were simultaneously observed. Other two patients $(8.3 \%)$ showed multiple bands corresponding to the three rearrangements: b2a2, b3a2 and e1a2 (Figure 1A, lane 5). The presence of these transcripts was confirmed by nested PCR using specific primers for each rearrangement. During follow-up of one of these patients, the three bands were detected even after 17 months of treatment with interferon (IFN- $\alpha$ ) and hydroxyurea. However, after 7 months of therapy with Imatinib mesylate, we observed by multiplex-PCR that the three transcripts had disappeared. This result was verified by specific nested PCR for each transcript.

In one case of CML, a variant rearrangement was observed, with a DNA size of $210 \mathrm{bp}$, which was not in accordance with any of the bands usually observed in CML (Figure 1B, lane 2). DNA amplification products were sequenced by Macro-Gene Ind. (Japan), using an Applied Biosystems 373xl DNA Analyzer. The sequence obtained was compared with well-known sequences using the BLAST Human Genome software. Direct sequencing of this cDNA showed a b3a3 variant rearrangement and deletion of $\mathrm{ABL}$ exon a2 sequences.

Among the 20 patients with AL (14 adults and 6 children), we observed 4 bcr-abl $(+)$ adults (20\%); three of these patients were classified as ALL (B-lineage) and one as AML (Table 1). Two of the B-lineage ALL patients (ages 28 and 51, respectively) showed the b2a2 transcript (Figure 1B, lane 3), and the other one (age 15) showed e1a2 (Figure 1B, lane 5). The patient with bcr-abl(+) AML (age 30) pre-

Table 1 - Types of bcr-abl transcripts in clinical samples.

\begin{tabular}{lcc}
\hline Number of patients (\%) & Transcript type & Hematological disorders \\
\hline $10 / 24(41.7 \%)$ & b2a2 & CML \\
$9 / 24(37.5 \%)$ & $\mathrm{b} 3 \mathrm{a} 2$ & $\mathrm{CML}$ \\
$2 / 24(8.3 \%)$ & $\mathrm{b} 2 \mathrm{a} 2-\mathrm{b} 3 \mathrm{a} 2$ & $\mathrm{CML}$ \\
$2 / 24(8.3 \%)$ & $\mathrm{e} 1 \mathrm{a} 2-\mathrm{b} 2 \mathrm{a} 2-\mathrm{b} 3 \mathrm{a} 2$ & $\mathrm{CML}$ \\
$1 / 24(4.2 \%)$ & $\mathrm{b} 3 \mathrm{a} 3$ & $\mathrm{CML}$ \\
$2 / 14(14.3 \%)$ & $\mathrm{b} 2 \mathrm{a} 2$ & $\mathrm{~B}-\mathrm{ALL}$ \\
$1 / 14(7.1 \%)$ & $\mathrm{e} 1 \mathrm{a} 2$ & B-ALL \\
$1 / 6(16.6 \%)$ & $\mathrm{b} 3 \mathrm{a} 2$ & AML \\
\hline
\end{tabular}



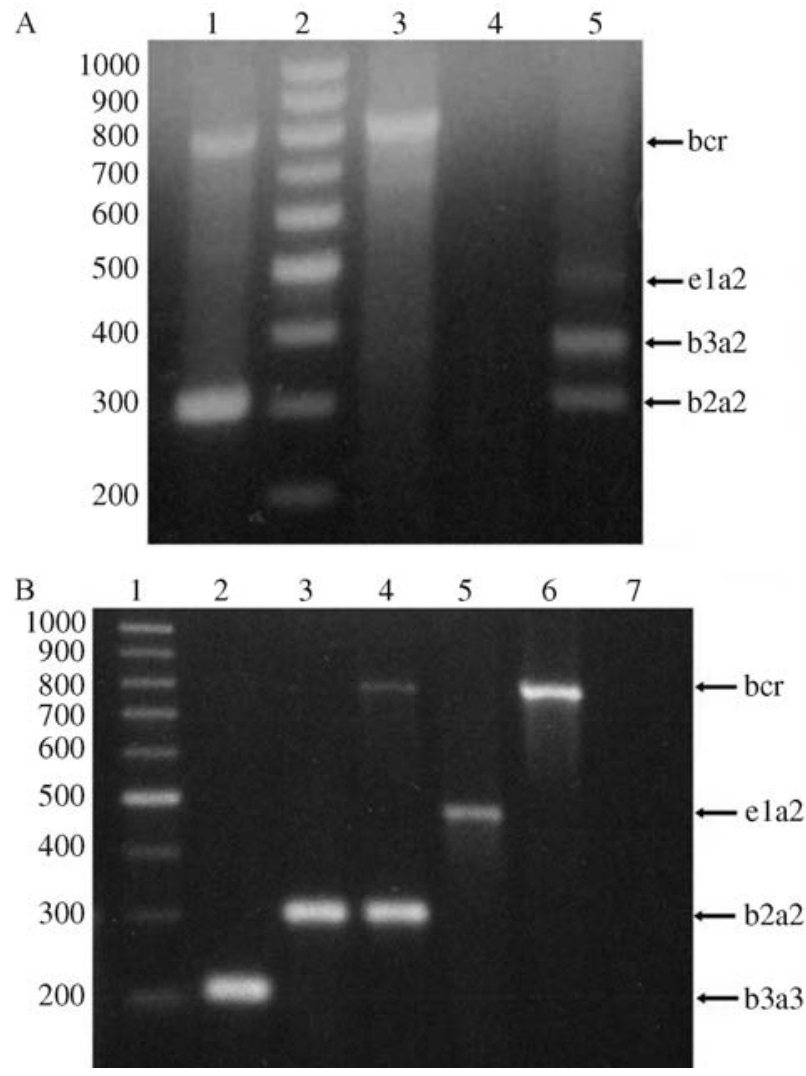

Figure 1 - A - Agarose gel electrophoresis of multiplex-PCR products in patient samples. Lane 1: b2a2 positive CML patient. Lane 2: molecular weight marker. Lane 3: BCR-ABL(-) ALL, the 808 bp product corresponds to the normal BCR gene. Lane 4: negative control. Lane 5: three bands observed in a CML patient, corresponding to e1a2 (481 bp), b2a2 (310 bp) and b3a2 (385 bp), respectively. The presence of these transcripts was confirmed by nested PCR. B - Detection of a variant rearrangement (b3a3) by multiplex-PCR. Lane 1: molecular weight marker. Lane 2: a $210 \mathrm{bp}$ band corresponding to the $\mathrm{b} 3 \mathrm{a} 3$ rearrangement in a CML patient. Lane 3: BCR-ABL (+) ALL, Lane 4: CML patient with b2a2 rearrangement. Lane 5: BCR-ABL $(+)$ ALL with e1a2 rearrangement. Lane 6: BCR-ABL(-) ALL, the 808 bp band corresponds to the normal BCR gene. Lane 7: negative control.

sented the b3a 2 rearrangement. The bcr-abl(+) ALL cases $(\mathrm{n}=3)$ presented the same phenotype as common B-ALL, with aberrant expression of myeloid antigens. All the bcr$\mathrm{abl}(+)$ AL cases were cytogenetically confirmed and then verified by nested PCR. Only one band of the normal BCR gene was observed in the BCR-ABL-negative cases.

Amplification products were not observed when multiplex-PCR was carried out with genomic DNA, which is frequently observed as the main contaminant in RNA extraction.

The sensitivity of multiplex-PCR in the detection of BCR-ABL transcripts was $1 / 100\left(10^{-2}\right)$, while that of nested PCR was $1 / 10.000\left(10^{-4}\right)$. Although nested PCR is the technique of choice for detecting specific transcripts, multiplex-PCR is useful in detecting simultaneously different transcripts which are present at high levels, as it is the case in untreated $\mathrm{b} 3 \mathrm{a} 3$ patients.
Our results indicate that the co-expression of both transcripts $\mathrm{b} 2 \mathrm{a} 2$ and $\mathrm{b} 3 \mathrm{a} 2$ in patients with CML is about $8.3 \%$. This value is similar to those described by Léglise et al. (1996). However, other authors have reported an incidence of up to $20 \%$ for the simultaneous presence of both transcripts (Marcelle et al., 1989). This could be explained as the result of an alternative splicing mechanism, rather than by the presence of two different clones; and, as the disease progresses, only one of them would prevail (Léglise et al., 1996).

The association of e1a2 (p190) with the two major transcripts (b2a2 and b3a2) was observed in 2 CML patients at diagnosis, and these findings were confirmed by nested PCR. Although the presence of ela 2 mRNA has been rather associated with bcr-abl(+) ALL, Van Rhee et al. (1996) found that $88 \%$ of CML patients at diagnosis and $100 \%$ in blastic crisis presented levels of e1a2 transcripts that can be detected by quantitative PCR. In a quantification test by competitive PCR, they demonstrated that the number of e1a2 transcripts in CML was approximately four times smaller than the number of b2/b3a 2 transcripts. These findings agree with those of Saglio et al., (1996), who observed that the quantity of ela 2 mRNA in CML in chronic phase represents approximately $20-30 \%$ of the total bcr-abl transcripts. The biological significance of the presence of e1a2 transcripts in CML at diagnosis is unclear. The low level of ela2 transcripts detected by Van Rhee et al. (1996) may not be significant for the pathogenesis of the disease; however, levels which are detectable by multiplex-PCR (sensitivity 1/100) could be relevant for the progression of the disease. A greater number of cases need to be evaluated with quantitative assays to establish a correlation between the presence of e1a2 transcripts (p190) at diagnosis and the progression of the disease.

One CML case showed a variant type of BCR-ABL fusion transcript. The directly sequenced PCR product revealed a b3a3 junction and absence of ABL exon 2-derived sequences. The frequency of such variant rearrangements is very low in both CML and ALL, and few cases have been reported in the literature (Iwata et al., 1994; Otazu et al., 2002; Liu et al., 2003; Paz-Y-Mino et al., 2003). These observations confirm the great genetic heterogeneity produced when a bcr-abl rearrangement occurs.

The identification of bcr-abl transcripts in AL is relevant for prognosis, therapeutic staging, and the follow-up of minimal residual disease (MRD). The rearrangement that encodes protein p190 (e1a2) is the most frequent in bcr-abl $(+)$ ALL. It is found in approximately $66 \%$ of adults and $90 \%$ of children with bcr-abl(+) ALL. In this study, two of the three cases of bcr-abl(+) ALL presented the b2a2 transcript and the third one the e1a2. Upon manifestation of the first clinical symptoms, when the level of the rearranged transcripts is relatively high, multiplex-PCR allows the detection of different types of transcripts in bcr-abl(+) ALL, allowing the follow-up of MRD by nested PCR. 
In conclusion, multiplex-PCR allows rapid, specific and simultaneous detection of the three most frequent bcrabl transcripts in patients with CML and AL, and other less frequent variants like the $\mathrm{b} 3 \mathrm{a} 3$ rearrangement.

\section{Acknowledgments}

We thank Asociación Pro Ayuda al Departamento de Oncohematología del Hospital Clínicas (A.P.R.A.D.O.C.) and Arcor Foundation for their support by donating the laboratory where this research was carried out.

\section{References}

Chomczynski P and Sacchi N (1987) Single-step method of isolation by acid guanidinium thiocyanate-phenol-chloroform extraction. Anal Biochem 162:156-159.

Crist W, Carrol A, Shuster J, Jackson J, Head D, Borowitz M, Behm F, Link M, Steuber P, Ragab A, et al. (1990) Philadelphia chromosome-positive childhood acute lymphoblastic leukemia: Clinical and cytogenetic characteristics and treatment outcome: A Pediatric Oncology Group (POG) study. Blood 76:489-494.

Cross N (1996) Detection of BCR-ABL in hematological malignancies by RT-PCR. In: Coterr FE (ed) Molecular Diagnosis of Cancer. Humana Press Inc., Totowa, pp 25-35.

Cross N, Melo J, Feng L and Goldman J (1994) An optimized multiplex polymerase chain reaction (PCR) for detection of BCR-ABL fusion mRNA in hematological disorders. Leukemia 8:186-189.

Heisterkamp N, Knoppel E and Groffen J (1988) The first BCR gene intron contains breakpoints in Philadelphia chromosome-positive leukemia. Nucleic Acid Res 16:1006910081.

Iwata S, Muzatani S, Nakazawa S and Yata J (1994) Heterogeneity of the breakpoint in the ABL gene in cases with BCR/ ABL transcript lacking ABL exon a2. Leukemia 8:16961702.
Kawasaki ES, Clark SS, Coyne MY, Smith SD, Champlin R, Witte ON and Mc Cormick FP (1988) Diagnosis of chronic myeloid and acute lymphocytic leukemia by detection of leukemia-specific mRNA sequences amplified in vitro. Proc Natl Acad Sci USA 85:5698-5702.

Léglise $\mathrm{MCH}$, Pluchon-Rivière E, Geneviève Le Calvez JF, Berthou CH, Autrand C, Luc Sensebè DB, Balcon D and Le Roux AM (1996) Molecular diagnosis and follow-up in myeloproliferative syndromes and acute leukemias: Correlation between expression of fusion transcripts and disease progression in chronic myeloid leukemia. Leuk Lymphoma 21:187-199.

Liu L, Tanaka H, Ito K, Kyo T and Kimura A (2003) Chronic myelogenous leukemia with e13 a3 (b2a3) type of transcript having a DNA breakpoint between ABL exons a2 and a3. Am J Hematol 74 :268-272.

Marcelle C, Gale RP, Prokocimer M, Berrebe A, Merle Beral H and Canani E (1989) Analysis of BCR-ABL mRNA in chronic myelogenous leukemia patients and identification of a new BCR - Related sequence in human DNA. Genes Chromosomes Cancer 1:172-179.

Otazu I, Belen Rivero M, Olicio R, Pinto A, Zalcberg I and Seuanez H (2002) A rare, in-frame BCR-ABL fusion (e13a3) in a patient with an aggressive chronic myeloid leukemia. Acta Haematol 108:150-153.

Paz-Y-Mino C, Arevalo M and Leone P. (2003). B3/A3 rearrangement in a patient with chronic myeloid leukemia. Leuk Lymphoma 44:375-376.

Rowley JD (1973) A new consistent chromosomal abnormality in chronic myelogenous leukemia identified by quinacrine fluorescence and Giemsa staining. Nature 243:290-293.

Saglio G, Pane F, Gottardi E and Frigeri MR (1996) Consistent amounts of acute leukemia-associated P190 BCR/ABL transcripts are expressed by chronic myelogenous leukemia patients at diagnosis. Blood 87:1075-1080.

Van Rhee F, Hochhaus A, Feng, L, Melo J, Goldman J and Cross N (1996) p190 BCR-ABL mRNA is expressed at low level in $\mathrm{p} 210$ positive chronic myeloid and acute lymphoblastic leukemias. Blood 87:5213-5217.

Associate Editor: Emmanuel Dias Neto 